\title{
DFT Conformational Study of the Monomethoxycalix[5]arene
}

\author{
Kwangho Kim, Sang Hyun Lee, and Jong-In Choe* \\ Deparment of Chemistry, Chung-Ang University, Seoul 156-756. Korea. 'E-mail: choejiacauack' \\ Received Atgust 20,2008
}

\begin{abstract}
In this study, we have performed $D F T$ calculations to investigate the conformational characteristics and the hydrogen bonds of the monomethyl ether of $p$-tert-butylcalix [5] arene (1: 5,11,17,23,29-Penta-tert-butyl-31methoxy-32,33,34,35-tetrahydroxycalix[5]arene). The structures of different confomers of 1 were optinized by using $\mathrm{B} 3 \mathrm{LYP} / 6-3 \mathrm{l}+\mathrm{G}(\mathrm{d}, \mathrm{p})$ method. The relative stability of the various confomers of 1 is in the following order: 2,3-alternate (most stable) $>1$-partial-cone $\sim 1,2$-altemate $>$ cone $>2$-partial-cone $>3$-partial-cone $\sim 2,4-$ altemate $\sim 1,3$-altemate. The primary factor affecting the relative stabilities of the various conformers of the monomethoxy-t-butylcalix[5] arene (1) are the number of the intramolecular hydrogen bonds.
\end{abstract}

Key Words : DFT, B3LYP/6-31+G(d,p), Methoxycalix[5]arene, Confonmer, Hydrogen bond

\section{Introduction}

The calixarenes are particularly attractive as a basic skeleton for new supramolecular systems due to their welldefined molecular framework. ${ }^{3}$ Among the varying structures of calix[n]arenes, pentameric analogue calix[5]arenes ${ }^{2}$ (1-3) has received relatively less attention due to their difficulties both in the synthesis and in the selective derivatization compared to the other widely employed members of calixarenes having four (4-8), six, or eight repeating units. The relative stabilities of the various conformations of calix[4]aryl derivatives are determined by experimental and theoretical methods. ${ }^{3-10}$

Four different conformations of the tetramethoxy-p-tertbutylcalix[4]arene ( 6 ) have been calculated, and the trend (in the order of partial cone (most stable) $>$ cone $>1,2$-alternate - 1.3-alternate) is consistent with the relative free energies obtained from the XVR spectroscopic data. ${ }^{5}$ Reinhoudt $e t$ al. have also reported both the calculated and the experimental results of conformational distributions of 6 and partially methylated calix[4]arenes. ${ }^{6}$ We have studied the conformational characteristics of 6 by using the $\mathrm{HF} / 6-31 \mathrm{G}(\mathrm{d}, \mathrm{p})$ method, which reveals that the partial-cone conformer is $0.31 \mathrm{kcal} / \mathrm{mol}$ more stable than the cone. ${ }^{8}$ However, our conformational studies of the tetraethyl ester (7) of the $p$ tert-butylcalix[4]arene by using B3LYP/6-311+G(d,p)/HF/ $6-31 \mathrm{G}$ calculations suggest that the cone conformational isomer is slightly more stable than the partial-cone analogue. ${ }^{9}$ The relative stability of different conformers for the trimethyl ethers of the monodeoxycalix[4]arene (8) was investigated by performing a ${ }^{1} \mathrm{H}$ NMR experiment ${ }^{10 \mathrm{it}}$ as well as by $a b$ initio and $D F T$ calculations. ${ }^{10 \mathrm{~b}}$ Recently we have reported the $D F T$ calculation results for the conformers and hydrogen bondings of $t$-butylcalix[5] arene (2) and $t$-butylcalix [4]arene (4). ${ }^{11}$ The first objective of this research is to determine the relative stability of different conformational isomers ${ }^{12}$ for 1 by using the $D F T$ calculation. The second objective is to investigate the intramolecular hydrogen bonds ${ }^{13}$ by the four hydroxyl groups of the monomethoxy-t-butylcalix[5]arene (1).

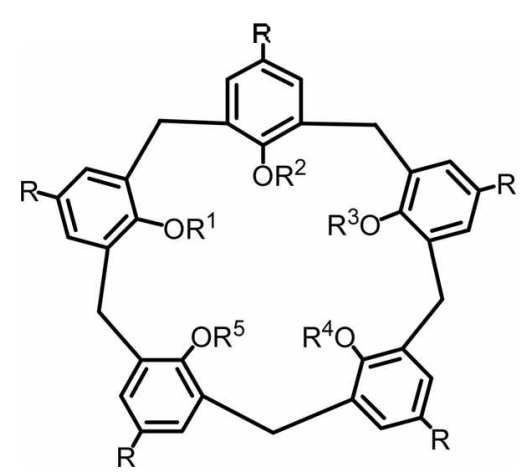

\begin{tabular}{|c|c|c|c|c|c|c|c|}
\hline & Molecule & $\mathrm{R}$ & $\mathrm{R}^{\mathrm{l}}$ & $\mathrm{R}^{2}$ & $\mathrm{R}^{3}$ & $\mathrm{R}^{\downarrow}$ & $\mathrm{R}^{5}$ \\
\hline 1 & Methoxy-t-butylcalix [5]arene & t-Butyl & $\mathrm{CH}_{3}$ & $\mathrm{H}$ & $\mathrm{H}$ & $\mathrm{H}$ & $\mathrm{H}$ \\
\hline 2 & $t$-Butylcalix[5]arene & $t$-Butyl & $\mathrm{H}$ & $\mathrm{H}$ & $\mathrm{H}$ & $\mathrm{H}$ & $\mathrm{H}$ \\
\hline 3 & Calix[5]arene & $\mathrm{H}$ & $\mathrm{H}$ & $\mathrm{H}$ & $\mathrm{H}$ & $\mathrm{H}$ & $\mathrm{H}$ \\
\hline
\end{tabular}

Chart 1. ChemDraw Structures of Calix[5]arene and Monomethoxy-t-butylcalix[5]arene.

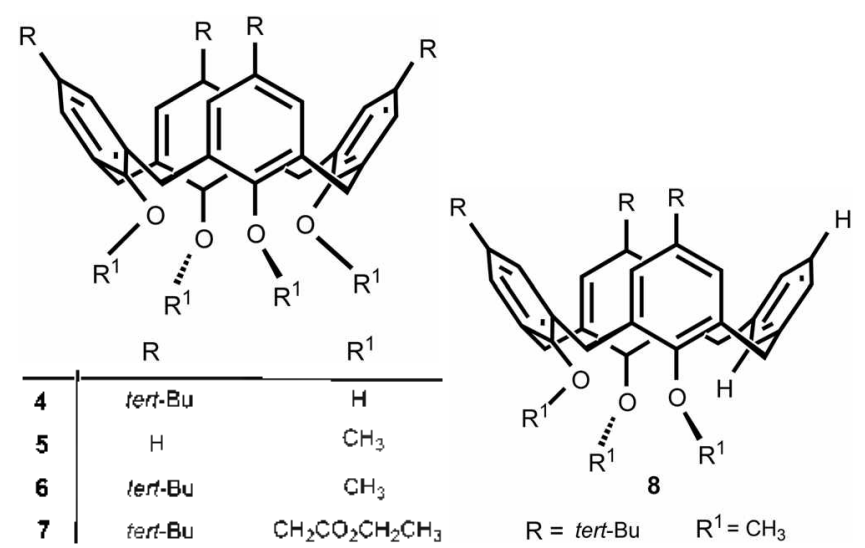

Chart 2. ChemDraw Structures of calix[4]aryl derivatives. $4=p$ tert-Butylcalix[4]arene. $5=$ Tetramethyl ether of calix[4]arene, $6=$ Tetramethyl ether of $p$-tert-butylcalix[4]arene. $7=$ Tetraethyl ester of $p$-tert-butylcalix[4]arene, $8=$ Trimethyl ether of $p$-tert-butylmonodeoxycalix[4]arene. 
Table 1. DFT B3LYP Optimized Energies" of the Various Conformers of 1

\begin{tabular}{|c|c|c|c|c|c|c|c|c|}
\hline Conformer & cone & $\operatorname{lpc}$ & $2 p c$ & $3 \mathrm{pc}$ & $12 \mathrm{a}$ & $13 a$ & $23 a$ & $24 a$ \\
\hline \multicolumn{9}{|l|}{ Method } \\
\hline$/ 6-31 \mathrm{G}(\mathrm{d}, \mathrm{p})$ & -2553.6222 & -2553.6245 & -2553.6244 & -2553.6038 & -2553.6164 & -2553.6043 & -2553.6316 & -2553.6041 \\
\hline$\Delta E(\mathrm{kcal} / \mathrm{mol})^{-}$ & 5.91 & 4.46 & 9.54 & 17.13 & 4.50 & 17.40 & 0.00 & 17.22 \\
\hline $6-3 \mathrm{l}+\mathrm{G}(\mathrm{d} . \mathrm{p})$ & -2553.6932 & -2553.6949 & -2553.6866 & -2553.6770 & -2553.6948 & -2553.6831 & -2553.7002 & -2553.6753 \\
\hline$\Delta E$ (kcalmol) & 4.50 & 3.41 & 8.62 & 14.66 & 3.45 & 10.79 & 0.00 & 15.71 \\
\hline
\end{tabular}

"The unit of B3LYP energy is in a.u. "Conformet: lpc (1-partial cone) denotes that the anisole group having methoxy moiety is inverted. 2pce (2-partial cone) means that one phenyl group which is next to the anisole group is inverted, etc. (See Figure 1.). ' $\Delta E$ ( $\mathrm{kcal}$ mol) is the relative energy witl respect to the most stable conformation (2,3-alternate). Error limits in these calculations are about $0.01 \mathrm{kcal} / \mathrm{mol}$.

\section{Computational Methods}

The initial structures of monomethoxy-t-butylcalix[5]arene (1) were constructed by using HyperChem. ${ }^{14}$ In order to find optimized conformations, we executed a conformational search by using a simulated annealing method, which has been described in a previous publication. ${ }^{15}$ The conformational isomers of 1 obtained from $\mathrm{MM} / \mathrm{MD}$ calculations were fully re-optimized by using the quantum mechanical methods to estimate the absolute and relative energies of the different conformations of 1. AM1 semi-empirical optimizations followed by DFT calculations of 1 by using Gaussian $98^{16}$ were performed with an error limit of less than $0.01 \mathrm{kcal} / \mathrm{mol}$ for each conformer. The consecutive B3LYP/ $6-31 G(d, p)$ and B3LYP/6-31+G(d,p) optimizations of the final structures are done to include the diffuse function, the effect of electron correlation and the basis set with polarization function.

\section{Results and Discussion}

Conformational Characteristics of Monomethyl Ether of p-tert-Butylcalix[5]arene (1): (5,11,17,23,29-Penta-tertbutyl-31-methoxy-32,33,34,35-tetrahydroxycalix[5]arene).

It is well known that the calix[5]arenes ( 2 and 3 ) and calix[4]arene (4) form strong intramolecular hydrogen bonds among $\mathrm{OH}$ groups and represent the cone conformer as the most stable structure., ${ }^{3,11}$ Substitution of all the phenolic protons of a calix[4]arene by bulky alkyl groups generally leads to conformationally rigid structures like $7{ }^{9}$ However. when the substituent is small enough such as a methyl group, the resulting methyl ether 6 is no longer rigid, and any anisole ring can rotate via oxygen-through-the-annulus to give a mixture of the four possible conformers. ${ }^{5-8}$

The barrier for conformational interconversion diminish progressively as the $\mathrm{OH}$ groups of 2 are changed to $\mathrm{OMe}$ groups, ascribed to continuously diminishing intramolecular hydrogen bonding that is not offset by the corresponding increase in steric hindrance. ${ }^{12}$ It is interesting to investigate what kind of influence on the relative stabilities for the different conformers of monomethoxy-p-tert-butylcalix[5]arene (1) will be made by the substitution of one of the five p-tert-butylphenol rings in 2 with a methoxy-p-fert-butylbenzene. Although the rings of 1 are able to move through the annulus of the lower rim, the hydrogen bonds restrict the free rotation. Various conformations of 1 can be generated by the up/down orientation of the benzene rings.

The DFT optimizations without any constraint were carried out for the various conformers of the monomethyl ether of $p$-tert-butylcalix[5] arene (1). Table 1 shows the total and relative energies of the eight distinct conformers of 1 obtained by the B3LYP/6-31G(d,p) and B3LYP/6-31+G (d,p) calculations. The calculation results suggest that 2,3alternate conformer is the most stable one among the conformers of 1 in the following order: 2,3-alternate (most stable) $>1$-partial-cone $\sim$ 1,2-altemate - cone $>2$-partial-cone $>$ 1,3-alternate $>3$-partial-cone $\sim 2,4$-alternate.

We can sort the relative stabilities of eight conformers in Table 1 into four groups: the 2,3-altemate conformer is 3.4$4.5 \mathrm{kcal} / \mathrm{mol}$ more stable than cone, 1-partial-cone and 1,2alternate analogues, $8.8-10.8 \mathrm{kcal} / \mathrm{mol}$ more stable than 2 partial-cone and 1,3-altemate conformers, and 14.7-15.7 $\mathrm{kcal} / \mathrm{mol}$ more stable than 3-partial-cone and 2,4-altemate analogues. The primary factor affecting the relative stabilities of the various conformers of the monomethoxy-tbutylcalix[5]arene (1) are the number and strength of the intramolecular hydrogen bonds. Although there are many factors such as steric hindrances and electrostatic interactions determining the stability, each additional hydrogen bond contributes $4-5 \mathrm{kcal} / \mathrm{mol}$ for the stability of the conformers of 1.

Figure 1 shows the calculated stable structures showing the hydrogen bonds of the various conformers of the monomethyl ether of p-tert-butylcalix[5]arene. The 2,3-altemate conformer (Fig. 1(m)) of the 1 having four hydrogen bonds is the most stable. This result may be a kind of unusual outcome, since the adjacent $t$-butylbenzene rings of the 2,3alternate conformers produce more steric hindrance than other cases such as 1,3-alternate and 2,4-alternate. However, the hydrogen bondings of the 2,3-alternate conformer overcome the steric interferences.

Intramolecular Hydrogen Bonds of the Monomethyl Ether of p-tert-Butylcalix[5] arene (1): The DFT calculated distances and angles of intramolecular hydrogen bonds $(\mathrm{O}-\mathrm{H}$ $\cdots \mathrm{O}$ ) of $\mathbf{1}$ are listed in Table 2 . In general, if $\mathrm{O} \cdots \mathrm{O}$ distance is less than $3.0 \AA$, one interprets that the $(\mathrm{O}-\mathrm{H} \cdots \mathrm{O})$ hydrogen bond is relatively strong for this intramolecular case. ${ }^{13}$ The $\mathrm{O} \cdots \mathrm{O}$ calculated distances of $2.66-2.96 \AA$ in Table 2 suggest that our optimized values in $\mathbf{1}$ are in accord with the experimental distances (2.7-2.9 $\AA$ in Table 3 ) of the intra- 


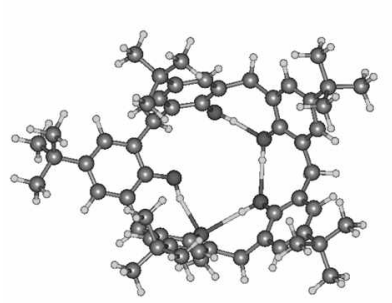

(a) Cone (top view; PosMol)

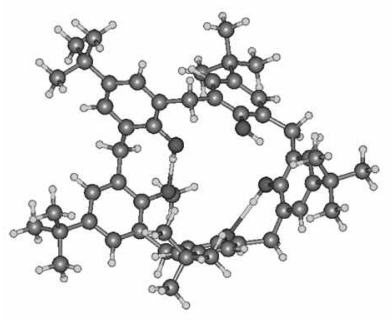

(e) 2-partial-cone (top view; PosMol)

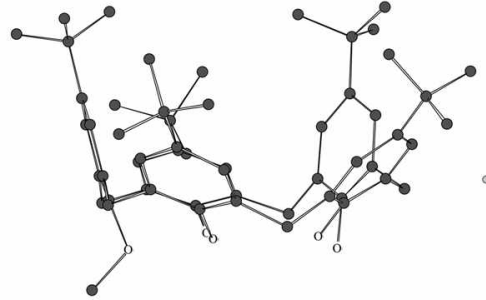

(b) Cone (side view; Chem3D)

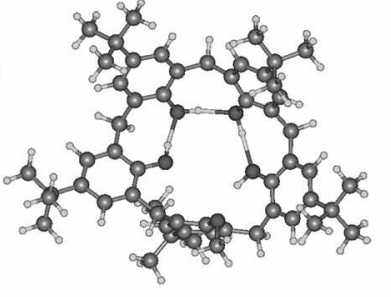

(c) 1-partial-cone (top view; PosMol)

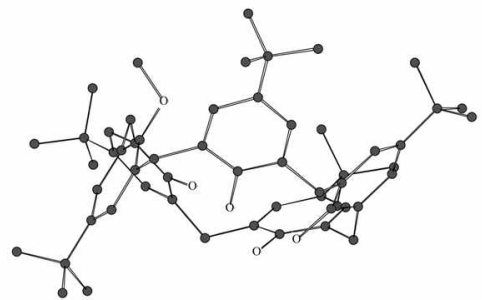

(d) 1-partial-cone (side view; Chem3D)

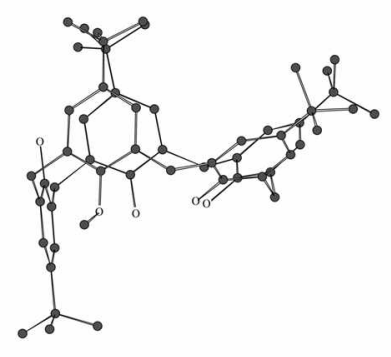

(f) 2-partial-cone (side view; Chem3D)

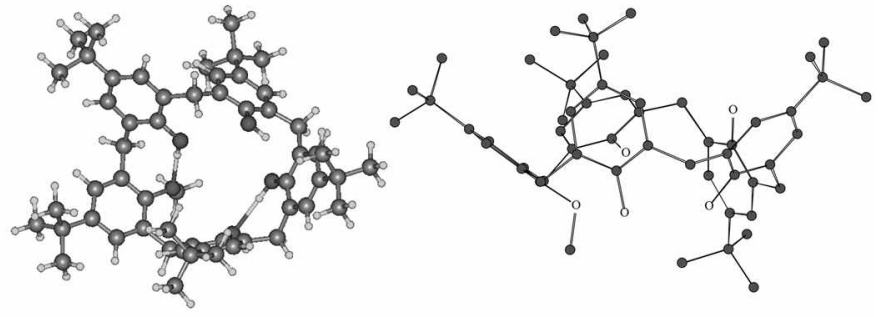

(g) 3-partial-cone (top view; PosMol)

(h) 3-partial-cone (side view; Chem3D)

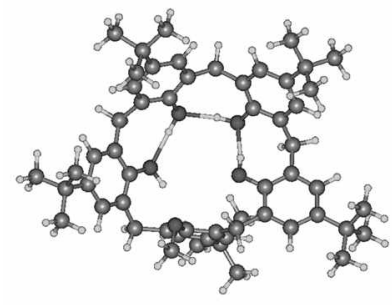

(i) 1,2-alternate (top view; PosMol)

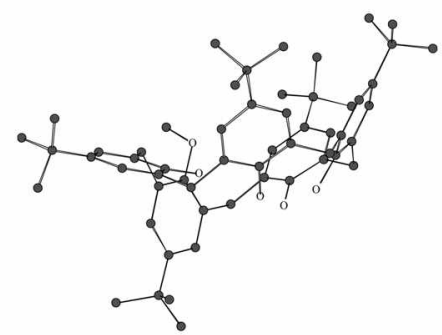

(j) 1,2-alternate (side view; Chem3D)

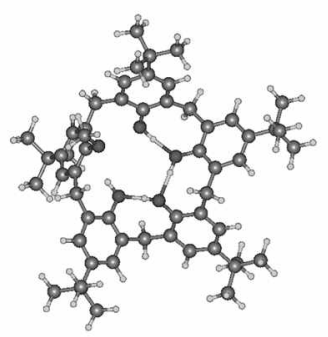

(k) 1,3-alternate (top view; PosMol)

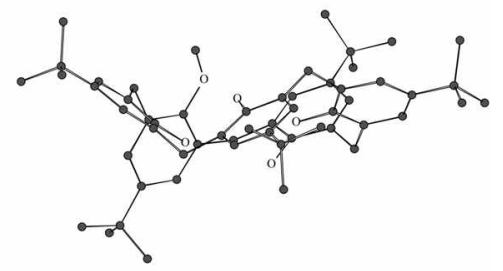

(I) 1,3-alternate (side view; Chem3D)

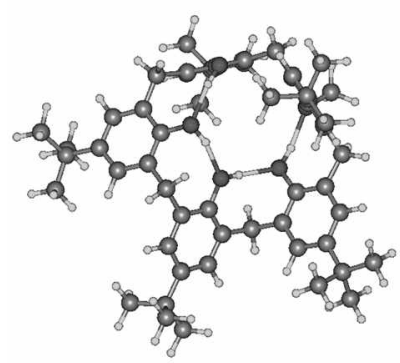

(m) 2,3-alternate (top view; PosMol)

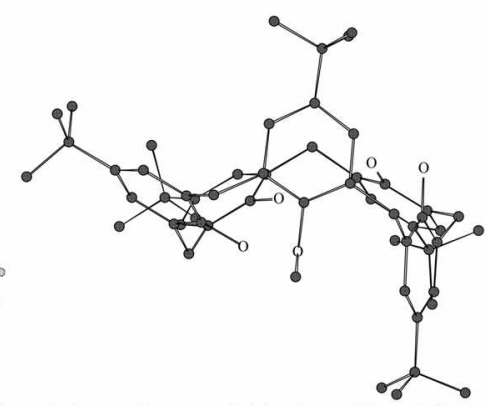

(n) 2,3-alternate (side view; Chem3D)

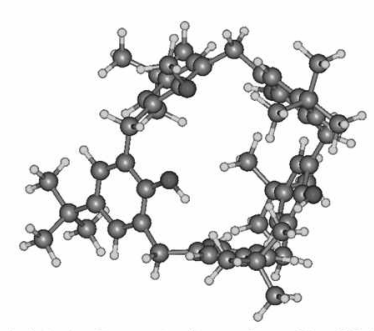

(o) 2,4-alternate (top view; PosMol)

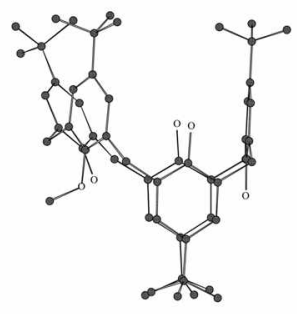

(p) 2,4-alternate (side view; Chem3D)

Figure 1. DFT B3LYP 6-31+G(d,p) optimized molecular structures of the confomers of 1 (p-terf-butyl monomethoxycalix[5] arene). (a) Top view of the cone conformer by PosMol ${ }^{12}$ with hydrogen bonds shown. (b) side view of the cone conformer by Chem $3 \mathrm{D}^{13}$ without hydrogen atoms. (c) top view of the 1-partial-cone conformer. (d) side view of the 1-partial-cone conformer. (e) top view of the 2-partialcone conformer. (f) side view of the 2-partial-cone conformer, $(\mathrm{g})$ top view of the 3-partial-cone conformer, (h) side view of the 3-partialcone conformer. (i) top view of the 1.2-altenate confomer. (j) side view of the 1.2-altemate confomer. (k) top view of the 1.3-altemate confomer. and (l) side view of the 1.3-altemate confomer, $(m)$ top view of the 2.3-altemate confomer, and (n) side view of the 2.3alternate conformer. (o) top view of the 2,4-alternate conformer, and (p) side view of the 2,4-alternate conformer.

molecular hydrogen bonds $(\mathrm{O} \cdots \mathrm{O})$ of the calixarenes $(2,3$, 4, and 5 ) obtained from Cambridge Structure Database. ${ }^{17.21}$

Table 2 also lists the DFT calculated $\mathrm{H} \cdots \mathrm{O}$ distances of 1 . If $\mathrm{H} \cdots \mathrm{O}$ distance is less than $2.0 \AA$, one judges that the $(\mathrm{O}-\mathrm{H}$ $\cdots O$ ) hydrogen bond is relatively strong for intramolecular case. ${ }^{13}$ The $\mathrm{H} \cdots \mathrm{O}$ distances of $1.71-2.00 \AA$ in Table 2 suggest that the hydrogen bondings in the molecule (1) are tairly strong. Also, one recognizes that the $(\mathrm{O}-\mathrm{H} \cdots \mathrm{O})$ hydrogen bond is stronger if the $(\mathrm{O}-\mathrm{H} \cdots \mathrm{O})$ angle is closer to $180^{\circ}$.
Our calculated $\left(\mathrm{O}-\mathrm{H}^{\cdots} \mathrm{O}\right)$ angles of $153^{\circ}-178^{\circ}$ in Table 2 tell that the hydrogen bondings in the molecule (1) are pretty strong.

In order to compare our calculated distances with the values of the stronger intramolecular hydrogen bonds of $t$ butylcalix[5]arene (2) and $i$-butylcalix[4]arene (4), we have tabulated the calculated hydrogen-bond data of $1,2^{11}$ and $4^{11}$ in Table 4. The average calculated $\mathrm{O} \cdots \mathrm{O}$ distances $(2.65-$ $2.80 \AA$ in Table 4 ) of the intramolecular hydrogen bonds of $t$ - 
Table 2. DFT Calculated Distances $(\AA)$ and Angles $(\mathrm{O}-\mathrm{H} \cdots \mathrm{O})$ of Intramolecular Hydrogen Bonds of 1

\begin{tabular}{|c|c|c|c|c|c|c|c|}
\hline Conformer & H-bond & 1 & 2 & 3 & 4 & Hac & Averag \\
\hline \multirow[t]{4}{*}{1 (cone) } & $0 \cdots 0$ & 3.208 & 2.904 & 2.830 & 2.905 & 4 & 2.962 \\
\hline & $\mathrm{H} \cdots \mathrm{O}$ & 2.239 & 1.929 & 1.886 & 1.958 & & 2.003 \\
\hline & $\mathrm{O}-\mathrm{H}$ & 0.971 & 0.976 & 0.975 & 0.971 & & 0.973 \\
\hline & Angle $\left(^{\circ}\right)$ & 174.3 & 177.0 & 162.1 & 164.3 & & 169.4 \\
\hline \multirow[t]{4}{*}{ 1(1-partial-cone) } & $0 \cdots 0$ & 2.853 & 2.757 & 2.748 & & 3 & 2.786 \\
\hline & $\mathrm{H} \cdots \mathrm{O}$ & 1.873 & 1.781 & 1.785 & & & 1.813 \\
\hline & $\mathrm{O}-\mathrm{H}$ & 0.982 & 0.984 & 0.978 & & & 0.981 \\
\hline & Angle $\left(^{\circ}\right)$ & 176.5 & 170.7 & 167.1 & & & 171.4 \\
\hline \multirow[t]{4}{*}{ 1(2-partial-cone) } & $0 \cdots 0$ & 2.906 & 2.861 & & & 2 & 2.884 \\
\hline & $\mathrm{H} \cdots \mathrm{O}$ & 1.933 & 1.916 & & & & 1.924 \\
\hline & $\mathrm{O}-\mathrm{H}$ & 0.976 & 0.975 & & & & 0.975 \\
\hline & Angle( $\left.{ }^{\circ}\right)$ & 174.2 & 162.4 & & & & 168.3 \\
\hline \multirow[t]{4}{*}{ 1(3-partial-cone) } & $0 \cdots 0$ & 2.754 & 2.990 & & & 2 & 2.872 \\
\hline & $\mathrm{H} \cdots \mathrm{O}$ & 1.805 & 2.018 & & & & 1.912 \\
\hline & $\mathrm{O}-\mathrm{H}$ & 0.974 & 0.973 & & & & 0.974 \\
\hline & Angle $\left(^{\circ}\right)$ & 164.0 & 175.0 & & & & 169.5 \\
\hline \multirow[t]{4}{*}{$1(1,2$-alteranate $)$} & $0 \cdots 0$ & 2.857 & 2.762 & 2.755 & & 3 & 2.791 \\
\hline & $\mathrm{H} \cdots \mathrm{O}$ & 1.876 & 1.785 & 1.793 & & & 1.818 \\
\hline & $\mathrm{O}-\mathrm{H}$ & 0.981 & 0.984 & 0.978 & & & 0.981 \\
\hline & Angle $\left(^{\circ}\right)$ & 177.5 & 171.4 & 166.8 & & & 171.9 \\
\hline \multirow[t]{4}{*}{1 (1,3-alteranate) } & $0 \cdots 0$ & 2.606 & 2.600 & 2.787 & & 3 & 2.664 \\
\hline & $\mathrm{H} \cdots \mathrm{O}$ & 1.624 & 1.634 & 1.888 & & & 1.715 \\
\hline & $\mathrm{O}-\mathrm{H}$ & 0.986 & 0.986 & 0.976 & & & 0.983 \\
\hline & Angle $\left(^{\circ}\right)$ & 173.0 & 164.8 & 151.8 & & & 163.2 \\
\hline \multirow[t]{4}{*}{$1(2,3$-alteranate $)$} & $0 \cdots 0$ & 2.757 & 2.791 & 2.867 & 2.789 & 4 & 2.801 \\
\hline & $\mathrm{H} \cdots \mathrm{O}$ & 1.846 & 1.851 & 1.907 & 1.822 & & 1.857 \\
\hline & $\mathrm{O}-\mathrm{H}$ & 0.978 & 0.979 & 0.978 & 0.979 & & 0.979 \\
\hline & Angle $\left(^{\circ}\right)$ & 153.7 & 159.6 & 166.6 & 168.7 & & 162.2 \\
\hline
\end{tabular}

"The number of intramolecular hydrogen bonds in the particular conformer.

Table 3. Experimental Distances $(\mathrm{O} \cdots \mathrm{O})$ of Intramolecular Hydrogen Bonds of Calixarenes

\begin{tabular}{|c|c|c|}
\hline Molecule \# & Molecule (CSD ${ }^{17}$ entry) & Average $(\AA)$ \\
\hline 2 & $t$-Butylcalix[5]arene (VETXUO ${ }^{18}$ ) & 2.894 \\
\hline 3 & Calix[5]arene (VETYAV ${ }^{18}$ ) & 2.780 \\
\hline 3 & Calix [5]arene (UKAGIW ${ }^{14}$ ) & 2.764 \\
\hline 4 & $t$-Butylcalix[4]arene (XAHMOI $\left.{ }^{21}\right)$ & 2.779 \\
\hline 5 & $t$-Butylcalix [4]crown-5-ether (VERLUA ${ }^{* 1}$ ) & 2.727 \\
\hline
\end{tabular}

butylcalix[4]arene (4) are shorter than the values (2.76-2.86 $\AA)$ of $t$-butylcalix[5]arene (2) and the values (2.79-2.96 $\AA$ ) of monomethoxy-t-butylcalix[5] arene (1).

The conformational study of 6 (tetramethyl ether of the $p$ tert-butylcalix[4]arene) by using the $\mathrm{HF} / 6-31 \mathrm{G}(\mathrm{d}, \mathrm{p}$ ) method suggested that the cone and partial-cone conformers are 3-6 $\mathrm{kcal} / \mathrm{mol}$ more stable than the 1,2-alternate or 1,3-alternate. ${ }^{8}$ And. conformational studies of 7 (tetraethyl ester of the $p$ tert-butylcalix[4]arene by using B3LYP $/ 6-311+\mathrm{G}(\mathrm{d} . \mathrm{p}) / \mathrm{HF} /$ 6-31G calculations report that the cone and partial-cone
Table 4. DFT B3LYP $/ 6-31+G(d, p)$ Calculated Average Distances $(\mathcal{A})$ and Angles of Intramolecular Hydrogen Bonds of 1, 2, and 4

\begin{tabular}{llccc}
\hline Confomer & H-bond & $\mathbf{1}^{*}$ & $\mathbf{2}^{h}$ & $\mathbf{4}^{h}$ \\
\hline cone & $\mathrm{O} \cdots \mathrm{O}$ & 2.962 & 2.765 & 2.650 \\
& $\mathrm{H} \cdots \mathrm{O}$ & 2.003 & 1.783 & 1.683 \\
& $\mathrm{O}-\mathrm{H}$ & 0.973 & 0.986 & 0.991 \\
& Angle $\left({ }^{\circ}\right)$ & 169.4 & 173.1 & 164.0 \\
\hline 1-partial-cone & $\mathrm{O} \cdots \mathrm{O}$ & 2.786 & 2.810 & 2.718 \\
& $\mathrm{H} \cdots \mathrm{O}$ & 1.813 & 1.841 & 1.767 \\
& $\mathrm{O}-\mathrm{H}$ & 0.981 & 0.979 & 0.982 \\
& Angle $\left({ }^{\circ}\right)$ & 171.4 & 170.1 & 163.5 \\
\hline 1,2-alteranate & $\mathrm{O} \cdots \mathrm{O}$ & 2.791 & 2.768 & 2.796 \\
& $\mathrm{H} \cdots \mathrm{O}$ & 1.818 & 1.823 & 1.842 \\
& $\mathrm{O}-\mathrm{H}$ & 0.981 & 0.982 & 0.978 \\
& Angle $\left({ }^{\circ}\right)$ & 171.9 & 162.3 & 164.2 \\
\hline 1,3-alteranate & $\mathrm{O} \cdots \mathrm{O}$ & 2.664 & 2.861 & \\
& $\mathrm{H} \cdots \mathrm{O}$ & 1.715 & 1.890 & \\
& $\mathrm{O}-\mathrm{H}$ & 0.983 & 0.976 & \\
& Angle $\left({ }^{\circ}\right)$ & 163.2 & 172.6 & \\
\hline
\end{tabular}

"The average data from Table 2. "Values from reference 11.

conformers are also $5-11 \mathrm{kcal} / \mathrm{mol}$ more stable than the 1,2alternate or 1,3-alternate. ${ }^{9}$ However, the B3LYP/6-31+G $(d, p)$ calculated relative stabilities of 1 report that the energy difference between the most stable group (2,3-alternate cone, 1-partial-cone, 1,2-alternate and cone conformers) and the least stable group (3-partial-cone and 2,4-alternate analogues) is about $11-15 \mathrm{kcal} / \mathrm{mol}$.

\section{Conclusion}

The relative stabilities of the various conformers of the monomethoxy-p-tert-butylcalix[5] arene (1) are more dependent upon the number of the intramolecular hydrogen bonds than steric hindrance of adjacent rings.

$D F T$ B3LYP $/ 6-31+\mathrm{G}(\mathrm{d}, \mathrm{p})$ calculations of 1 suggest that the 2,3-alternate conformer is most stable. The most stable group (2,3-alternate, 1-partial-cone, 2-partial-cone and cone) is about $11-15 \mathrm{kcal} / \mathrm{mol}$ more comfortable than the least stable group (3-partial-cone and 2,4-alternate). Each hydrogen bond contributes $4-5 \mathrm{kcal} / \mathrm{mol}$ for the stability of the conformers of the calixarenes 1-4.

The $\mathrm{O} \cdots \mathrm{O}$ hydrogen bond distances of 2.66-2.96 suggest that the calculated values in the molecule 1 are in accord with the experimental distances $(2.7-2.9 \AA)$ of the intramolecular hydrogen bonds $(0 \cdots 0)$ of the calixarenes $(\mathbf{2 , 3 , 4}$, and $\mathbf{5})$.

Acknowledgments. The large portions of the computations were carried out with use of the computer facilities at the Research Center for Computational Science of The Okazaki National Research Institutes in Japan.

\section{References}

1. (a) Gutsche, C. D. Colitarenes; Royal Society of Chemistry 
Cambridge, 1989. (b) Colikarenes: A Versatile Class of Macroctchic Compounds; Vicens, I, Böhmer, V, Eds.; Kluwer Academic Publishers: Dordrecht, The Netherlands, 1991. (c) Gutsche, C. D. Calinarenes Revisited, The Royal Society of Chemisty: Cambridge, 1998.

2. (a) Kanamathareddy, S.; Gutsche, C. D. J. Am. Chem. Soc. 1993, 115, 6572. (b) Gordon, T. L. M.; Böhmer, V; Vogt, W. Temahedron Leff 1995, 36, 2445. (c) Barrett, G.; McKervey, M. A.; Malone, J. F.; Walker, A.; Arnaud-Neu, F.; Guerra, L.; Schwing-Weill, M.-J. J. Chem. Soc. Perkin Trons. 2 1993, 1475. (d) Pappalardo, S.; Parisi, M. F. J. Org. Chem. 1996, 61, 8724. (e) Anauld-Neu, F.; Fuangswasdi, S.; Notti, A.; Pappalardo, S.; Parisi, M. Angen: Chem. Inf. Ed 1998, 37, 112. (f) Giannetto, M.; Mori, G; Notti, A.; Pappalardo, S.; Paris, M. F. Anal. Chem, 1998, 70, 4631, (g) Salvo, G. D.; Gattuso, G.; Notti, A.; Parisi, M.; Pappalardo, S. J. Org. Chem. 2002, 67,684.

3. (a) Gutsche, C. D.; Bauer, L. J. Tetrahedron Lett. 1981, 22, 4763. (b) Gutsche, C. D.; Bauer, J. J. Am. Chem. Soc. 1985, 107, 6052.

4. (a) Grootenhuis, P. D. J.; Kollman, P. A.; Groenen, L. C.; Reinhoudt, D. N.; van Hummel, G. I.; Lgozzoli, F.; Andreetti, G. D. J. Am. Chent. Soc. 1990, 112,4165 , (b) Groenen, L. C.; van Loon, J.-D.; Verboom, W.; Harkema, S.; Cannati, A.; Lngaro, R.; Pochini, A.; Ugozzoli, F; Reinhoudt, D. N. $J$. Am. Chem. Soc. $1991,113,2385$.

5. (a) Harada, T.; Rudzinski, J. M.; Shinkai, S. J. Chem. Soc.. Perkin Trons. 1992, 2, 2109 . (b) Harada, T.; Rudzinski, I. M.; Shinkai, S. Temahedron 1993, 49, 5941. (c) Harada, T; Ohseto, F; Shinkai, S. Tetrohedron $1994,50,13377$.

6. (a) van Hoom, W. P.; Briels, W. J.; van Duynthoven, J. P. M.; van veggel, F. C. J. M.; Reinhoudt, D. N. $J$. Org. Chem. 1998, 63, 1299. (b) van Hoorn, W. P; Morshuis, M. G. H.; van Veggel, F. C. J. M.: Reinhoudt, D. N. J. Phis. Chem. 1998, 102, 1130 .

7. (a) Kim, K. S.; Suh, S. B.; Kim, J. C.; Hong, B. H.; Lee, E. C.; Yun, S.; Tarakeshwar, P.; Lee, J. Y.; Kim, Y.; Ilum, H.; Kim, H. G.; Lee, J. W; Kim, J. K.; Lee, H. M.; Kim, D.; Cui, C.; Youn, S. J.; Chung, H. Y.; Choi, H. S.; Lee, C.-W.; Cho, S. J.; Jeong, S.; Cho, J.-H. J. Am. Chent. Soc. 2002, 124, 14268. (b) Riehn, C.; Reimann, B.; Buchhold, K.; Barth, H.-D.; Vaupel, S.; Brutschy, B.; Tarakeshwar, P.; Kim, K. S. J. Chem. Phns. 2001, 115, 10045. (c) Blixt, J.; Detellier, C. J. Am. Chem. Soc. 1995, 117,8536 .

8. Choe, J.-1.; Lee, S. H.; Oh, D.-S. Bull. Korean Chem. Soc. 2004, 25,55 .

9. Choe, T.-I.; Lee, S. H. Bufl. Korean Chem. Soc. 2004, $25,553$.
10. (a) Fukazawa, Y.; Yoshimura, K.; Sasaki, S.; Yamazaki, M.; Okajima, T. Tetrahedron 1996, 52, 2301. (b) Lee, H. D.; Kim, K. H.; Lee, H. J.; Lee, S.; Nanbu, S.; Choe, J.-I. Bull. Korean Chen. Soc. 2006, 27, 508 .

11. Kim, K.; Park, S. J.; Choe, J.-I. Bull. Korean Chem. Soc. 2008, 29 , 1893.

12. Stewart, D. R.; Krawiec, M.; Kashyap, R. P.; Watson, W. H.; Gutsche, C. D. J. An. Chem. Soc. 1995, 117, 586.

13. (a) Jeffrey, G. A. An Introdtction to Hudrogen Bonding; Oxford Lniv. Press: Cambridge, 1997. (b) Pak, C.; Lee, H. M.; Kim, J. C.; Kim, D.; Kim, K. S. Struct. Chem. 2005, 16, 187.

14. HyperChem Release 6.3; Hypercube, Inc.: Waterloo, Ontario, Canada, 2001

15. Choe, J.-I.; Kim, K.; Chang, S.-K. Bull. Korean Chem. Soc. 2000, 21,465 .

16. Frisch, M. J.; Trucks, G. W.; Schlegel, H. B.; Scuseria, G E.; Robb, M. A.; Cheeseman, J. R.; Zakrzewski, V. G.; Montgomery, J. A. Jr.; Stratmann, R. E.; Burant, J. C.; Dapprich, S.; Millam, J. M.; Daniels, A. D.; Kudin, K. N.; Strain, M. C.; Farkas, O.; Tomasi, I.; Barone, V.; Cossi, M.; Cammi, R.; Mennucci, B.; Pomelli, C.; Adamo, C.; Clifford, S.; Ochterski, I.; Petersson, G A.; Ayala, P. Y.; Cui, Q.; Morokuma, K.; Malick, D. K.; Rabuck, A. D.; Raghavachari, K.; Foresman, J. B.; Cioslowski, J.; Ortiz, J. V.; Baboul, A. G; Stefanov, B. B.; Liu, G.; Liashenko, A.; Piskorz, P. Komaromi, I.; Gomperts, R.; Martin, R. L.; Fox, D. J.; Keith, T.; Al-Laham, M. A.; Peng, C. Y.; Nanayakkara, A.; Challacombe, M.; Gill, P. M. W.; Johnson, B.; Chen, W. Wong, M. W.; Andres, I. L.: Gonzalez, C.: Head-Gordon, M.: Replogle, E. S.; Pople, J. A. Gaussian 98, Revision A.11.3, Gaussian, Lnc.: Pittsburdh, PA, 1998.

17. Cambridge Stratcture Database: Cambridge Crystallographic Data Centre: Cambridge, U. K. 2008.

18. Clark, T. E.; Makha, M.; Raston, C. L.; Sobolev, A. N. Chtst. Growth Des. 2006, 6, 2783

19. Atwood, J. L.; Barbour, L. J.; Heaven, M. W.; Raston, C. L. Anger: Chem. 2003, 42, 3254 .

20. Brouwer, E. B.; Ldachin, K. A.; Enright, G D.; Ripmeester, J. A. Chen. Commm 2000, 1905.

21. Agnihotri, P.; Suresh, E.; Paul, P.; Ghosh, P. K. Eul: J. Inorg. Chen. 2006, 3369 .

22. Lee, S. J.; Chung, H. Y.; Kim, K. S. Bull. Korean Chem. Soc. 2004, 25,1061 .

23. Chem_D, Version 7.0; Cambridge Sott: Cambridge, MA, L.S.A., 2001. 